Supporting Information for

\title{
A Strongly Bonded Selenium/Microporous Carbon Nanofibers Composite as a High-Performance Cathode for $\mathrm{Li}$-Se Batteries
}

Yunxia Liu, Ling Si, Yichen Du, Xiaosi Zhou, * Zhihui Dai, * and Jianchun Bao

Jiangsu Key Laboratory of Biofunctional Materials, School of Chemistry and Materials

Science, Nanjing Normal University, Nanjing 210023, P. R. China

*(X.Z.) E-mail: zhouxiaosi@njnu.edu.cn. Telephone/Fax: +86-25-85891027.

*(Z.D.) E-mail: daizhihuii@njnu.edu.cn. Telephone/Fax:+86-25-85891051. 


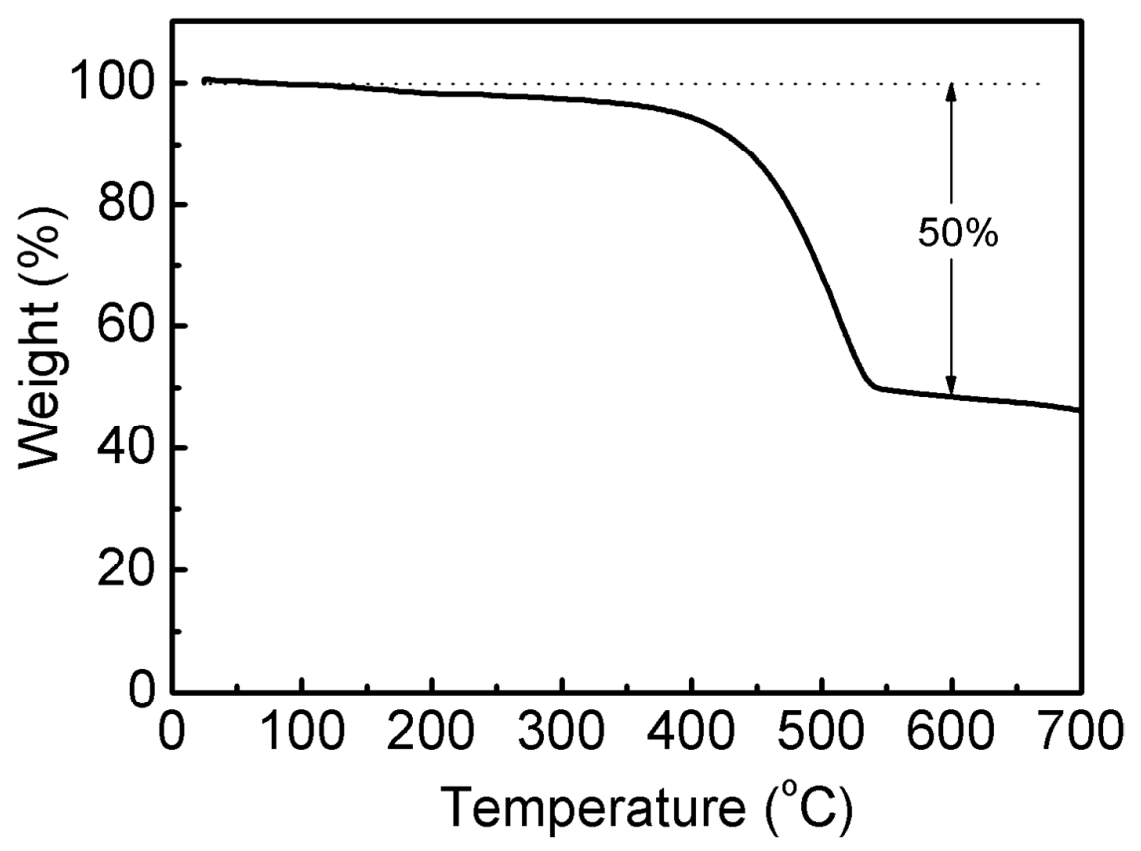

Figure S1. TGA curve of the Se/MCNF composite under argon flow with a heating rate of 10 ${ }^{\circ} \mathrm{C} \min ^{-1}$ from room temperature to $700{ }^{\circ} \mathrm{C}$. 

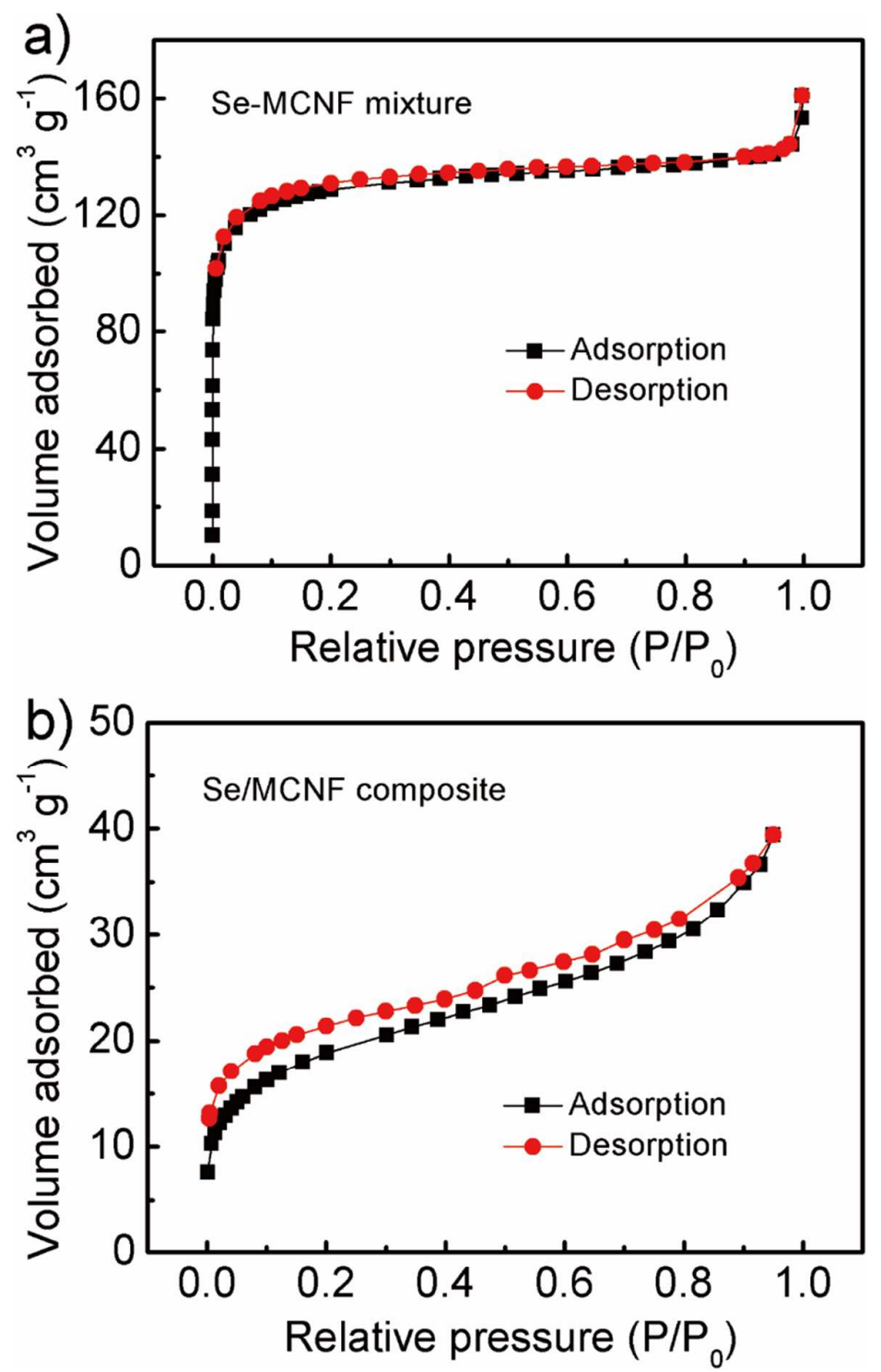

Figure S2. $\mathrm{N}_{2}$ adsorption-desorption isotherms of (a) the Se-MCNF mixture (without heat treatment) and (b) the Se/MCNF composite (with heat treatment) and the corresponding BET surface area are 402.5 and $66.2 \mathrm{~m}^{2} \mathrm{~g}^{-1}$, respectively. 


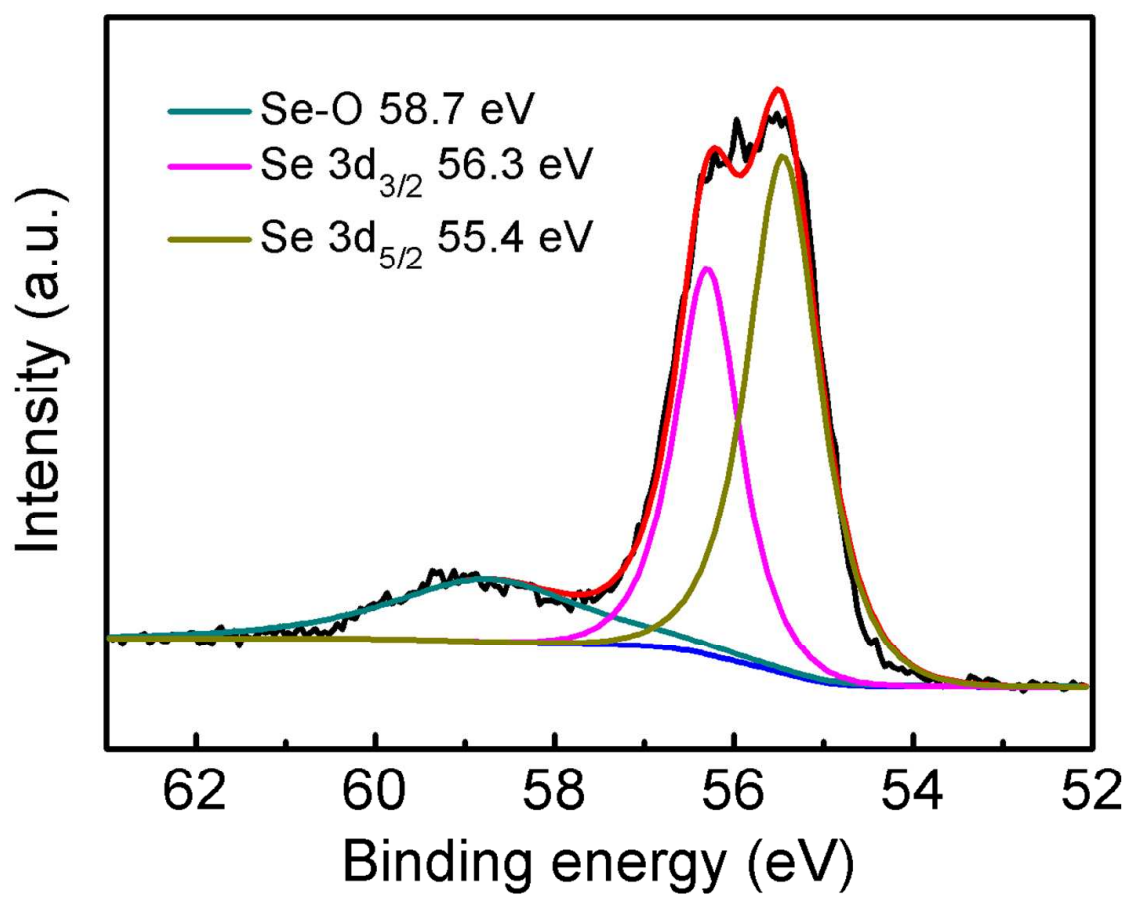

Figure S3. High-resolution Se 3d XPS spectrum of selenium powder. The peak at $58.7 \mathrm{eV}$ is attributed to the thin layer of Se-based oxides on the surface of Se particles owing to surface oxidation. 


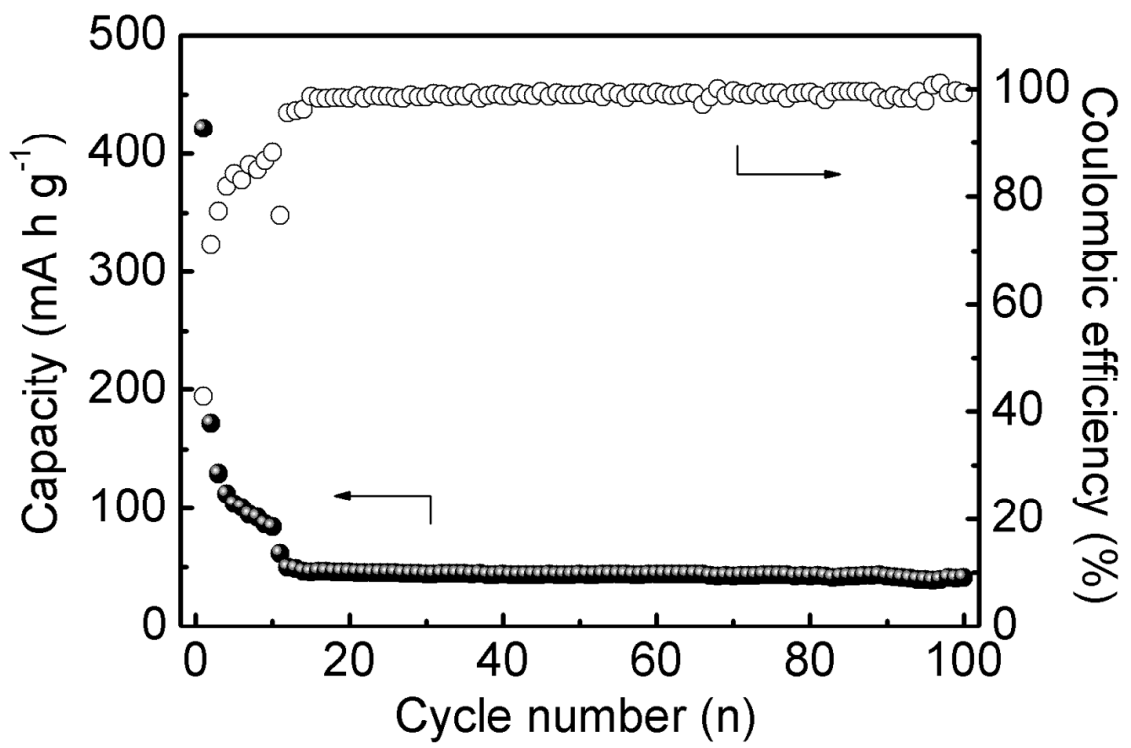

Figure S4. Cycling performance of the MCNF electrode in the voltage range of 1.0-3.0 V. The first 10 cycles are under $0.1 \mathrm{C}$ and the remaining 90 cycles are under $1 \mathrm{C}$. 


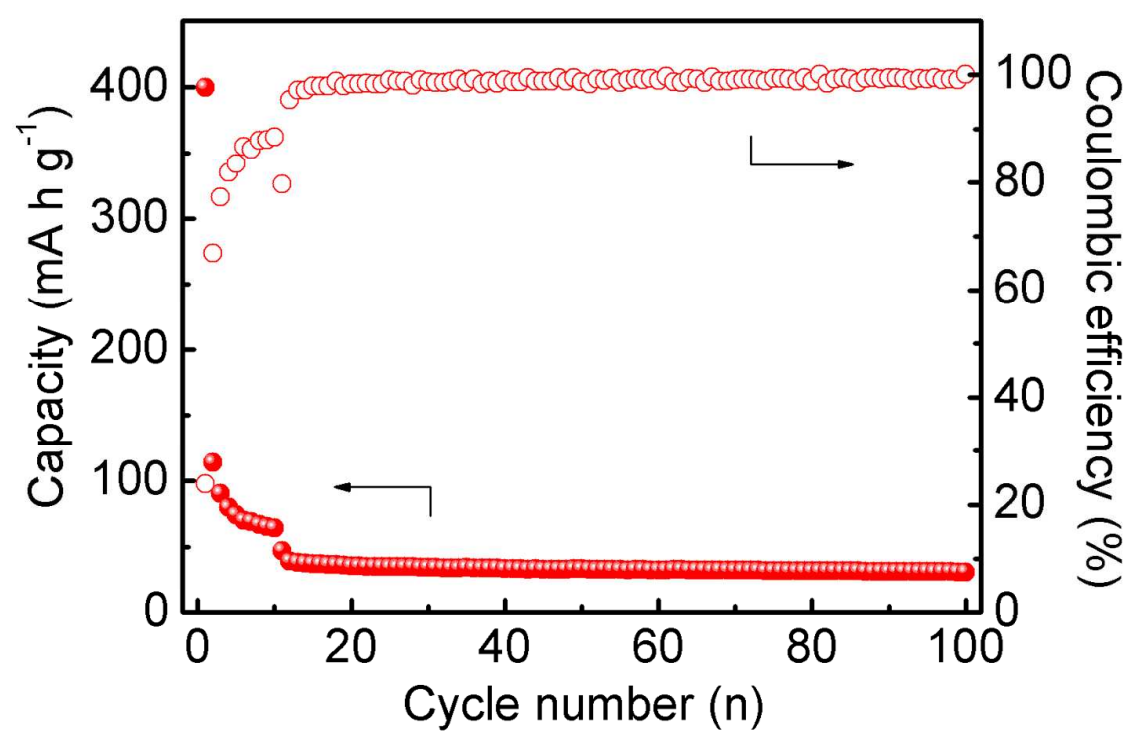

Figure S5. Cycling performance of the Se-MCNF mixture electrode in the voltage range of 1.0-3.0 V. The first 10 cycles are under $0.1 \mathrm{C}$ and the remaining 90 cycles are under $1 \mathrm{C}$. 

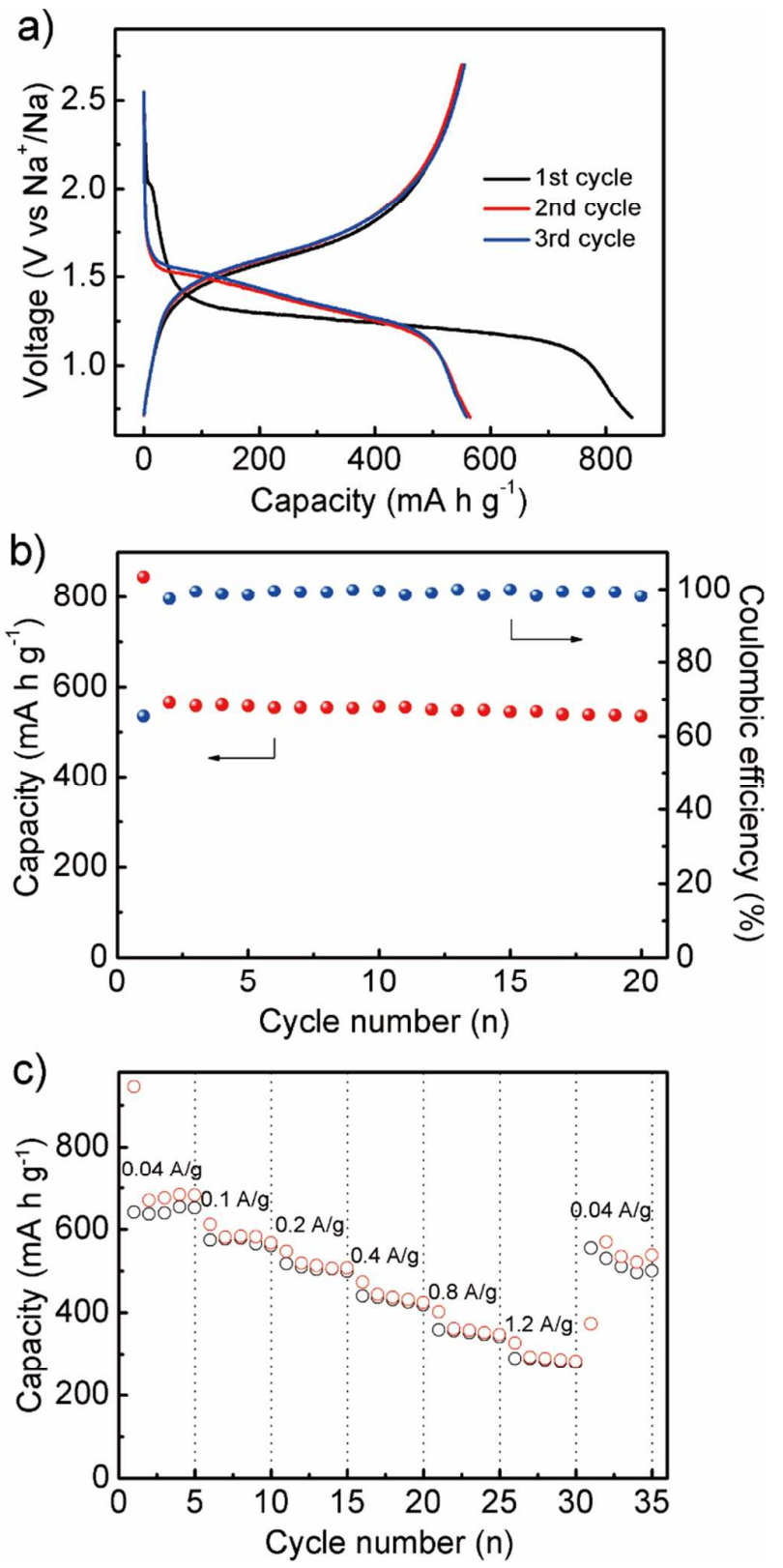

Figure S6. (a) Galvanostatic charge-discharge profiles of the Se/MCNF cathode in sodium-selenium $(\mathrm{Na}-\mathrm{Se})$ batteries at a current density of $0.1 \mathrm{~A} \mathrm{~g}^{-1}$. (b) Cycling performance and Coulombic efficiency of the Se/MCNF cathode in $\mathrm{Na}-\mathrm{Se}$ batteries under $0.1 \mathrm{~A} \mathrm{~g}^{-1}$. (c) Rate capability of the $\mathrm{Se} / \mathrm{MCNF}$ cathode in $\mathrm{Na}-\mathrm{Se}$ batteries under various current densities. 


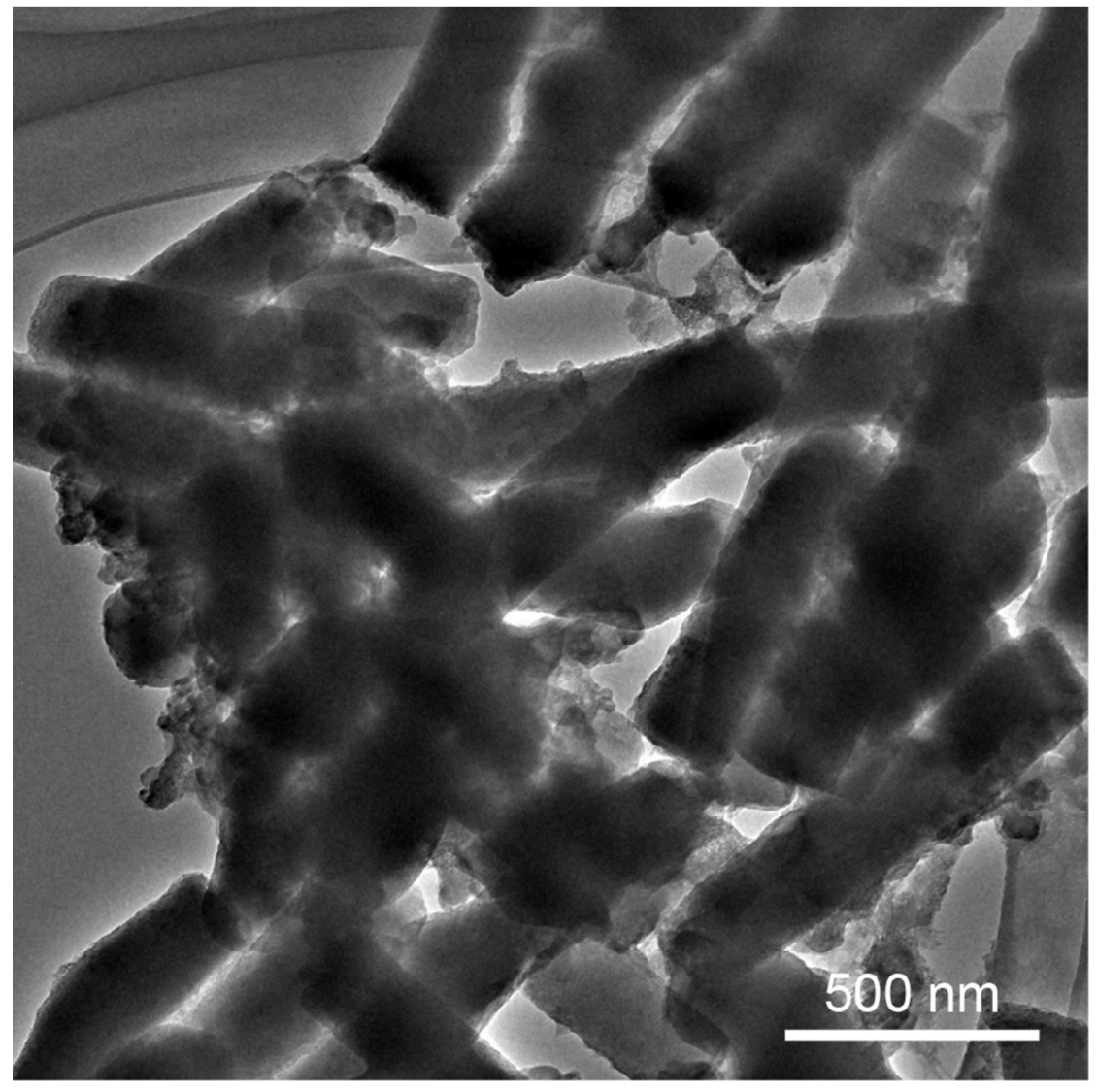

Figure S7. TEM image of the cycled Se/MCNF electrode material. 